\section{Modalidade e identificação na construção discursiva dos direitos humanos na contemporaneidade*}

Modality and identification in the contemporary discursive

Maria Clara Gomes Mathias CAVALCANTI (UFC) mclara54@gmail.com

Recebido em: 01 de nov. de 2019. Aceito em: 05 de maio de 2020.

*Comunicação apresentada no I Encontro Nacional em Linguística Sistêmico-Funcional, Fortaleza - CE, 07 de junho de 2019.

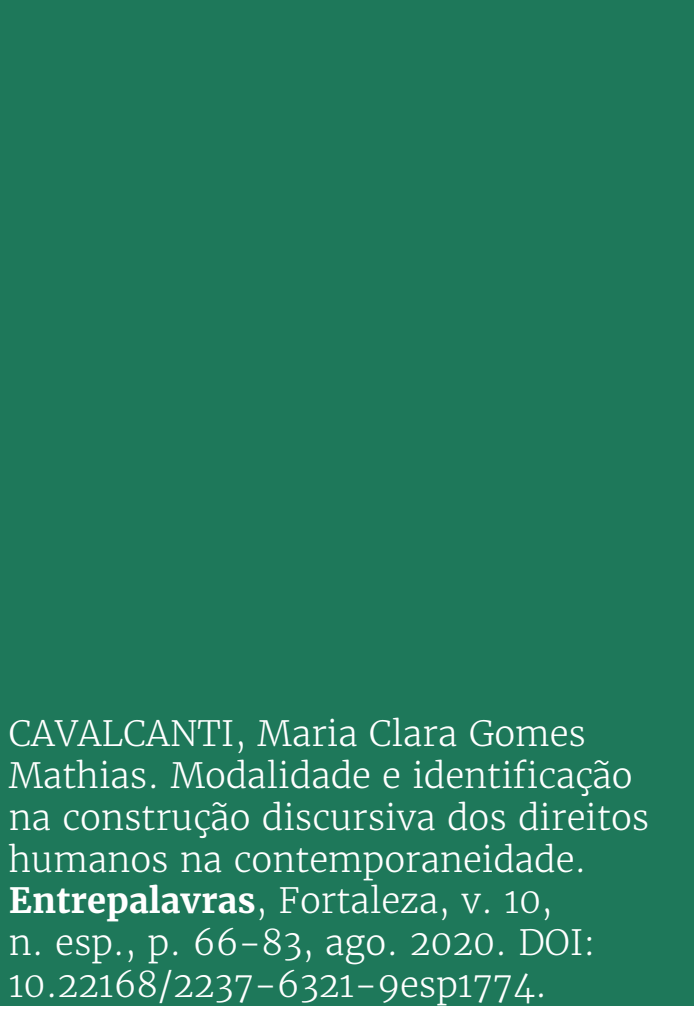

Resumo: O estudo aqui proposto voltase para a análise discursiva das formas de identificação emergentes em textos representativos da lei sobre direitos humanos e emblemáticos das lutas institucionais pela sua efetivação. Para tanto, examina-se a categoria modalidade, enquanto indício a partir do qual um usuário da linguagem participa (se engaja) em sua mensagem, expressando atitudes e julgamentos de vários tipos (EGGINS, 1994). Toma-se como referencial teórico a Análise de Discurso Crítica, de Norman Fairclough (1992, 2003), em sua operacionalização dos postulados da Linguística Sistêmico Funcional, de Halliday (1994), para um enquadre da linguagem como parte irredutível da vida social. Os dados analisados apontam que as formas de modalidade empregadas nos textos normativos, de natureza prescritiva, denotam um processo de esvaziamento da figura do sujeito. Afirmações peremptórias, vedações e cometimentos condizem com a construção de um regime de verdade, uma ordem mandamental cuja legitimidade última radica-se em uma verdade absoluta, uma ontologia. O efeito ideológico mais significativo é de objetividade e naturalização, como 
fundamentos para uma representatividade máxima. Já os textos que consubstanciam a luta por direitos, exibem marcas linguísticas de subjetividade (verbos em primeira pessoa e indicativos de processos mentais, advérbios intensificadores), tornandoos mais assumidamente políticos, designando os agentes históricos envolvidos nos processos de construção de sentidos para direitos humanos.

Palavras-chave: Modalidade. Direitos humanos. Discurso jurídico.

Abstract: The study proposed here focuses on the discursive analysis of emerging forms of identification in texts representative of the law on human rights and emblematic of institutional struggles for its implementation. To this end, we examine the category modality, as an indication from which a language user participates (engages) in his message, expressing attitudes and judgments of various kinds (EGGINS, 1994). The theoretical framework is Norman Fairclough's (1992, 2003) Critical Discourse Analysis, in its operationalization of Halliday's (1994) postulates of Functional Systemic Linguistics, for a framework of language as an irreducible part of social life. The data indicate that the forms of modality used in normative texts, of prescriptive nature, denote a process of emptying the figure of the subject. Peremptory affirmations, prohibitions, and commitments are consistent with the construction of a truth regime, a commandment order whose ultimate legitimacy is rooted in an absolute truth, an ontology. The most significant ideological effect is objectivity and naturalization, as foundations for maximum representativeness. Already the texts that substantiate the struggle for rights, exhibit linguistic marks of subjectivity (firstperson verbs and indicative of mental processes, intensifying adverbs), making them more admittedly political, designating the historical agents involved in the process of meaning construction for rights humans.

Keywords: Modality. Human rights. Legal discourse.

\section{Considerações Iniciais}

No presente trabalho, propõe-se, a partir da abordagem da Análise de Discurso Crítica - doravante ADC, uma atenta investigação do discurso jurídico sobre direitos humanos em duas práticas sociodiscursivas específicas: a prática jurídico-normativa e a prática de proteção institucional desses direitos. Perscrutamos formas linguísticas e estratégias de uso da linguagem que evidenciassem os meios através dos quais discurso e sociedade se entrecruzam na geração de novos e numerosos sentidos para os direitos humanos no mundo contemporâneo, considerados como plataforma emancipatória de direitos (PIOVESAN, 2011).

Entendemos que o aparato teórico e metodológico da ADC, de Norman Fairclough, oferece uma ampla gama de parâmetros e categorias para o confronto com os textos, proporcionando uma análise de discurso simultaneamente compromissada com questões sociais e linguísticas, visíveis na superfície dos textos. Fairclough, partindo do paradigma funcionalista dos estudos linguísticos, desenvolveu a ADC enquanto abordagem teórico-metodológica para o estudo da linguagem hábil para o desenvolvimento de análises de textos orientadas social 
v. 10 (esp) 66-83 ago. 2020 e linguisticamente. No presente trabalho, parte-se, portanto, de uma visão da língua como parte irredutível da vida social, em relação dialética com outros elementos desta, de forma que não se pode considerar uma sem a outra (FAIRCLOUGH, 2003).

No presente estudo, empreenderemos, especificamente a análise de um dos tipos de significado propostos pelo autor, o significado identificacional. Dessa forma, percorreremos os textos emblemáticos das duas práticas em estudo, a fim de examinar com detalhe as estratégias discursivas que servem a propósitos de identificação.

Fairclough (2003, p. 159) inicia sua abordagem das formas de identificação, apontando sua correspondência com a noção de estilo. Segundo ele, estilos são a dimensão discursiva dos modos de ser, das identidades. O autor destaca em suas palavras que a ênfase da expressão deve recair sobre o processo e não sobre o produto dos modos de ser, de forma que se prefere a expressão identificação. Assim, como veremos, o processo de identificação envolve efeitos constitutivos do discurso, que pode ser visto como uma dialética em que discursos são inculcados em identidades e ações.

Diante de tais reflexões, proporemos uma análise do aspecto discursivo das formas de identificação atuais, aquelas perceptíveis em textos representativos da lei sobre direitos humanos e das lutas institucionais pela sua efetivação. Para tanto, examinaremos os indícios dos textos representativos de uma categoria de análise específica: a modalidade (FAIRCLOUGH, 2003). Essa categoria diz respeito a aspectos da significação textual que contribui para a identificação na medida em que indica o grau de comprometimento com o que se fala ou escreve comprometimento com a verdade, a moral, a necessidade (obrigação), os valores daquilo que se diz.

\section{Uma breve incursão sobre a história do sentido de direitos humanos}

Antes de demonstrar o enfoque de análise, é preciso trazer considerações acerca dos direitos humanos e a história de sua emergência e contínuas transformações, assim como o status que essa ordem de direitos assume perante às sociedades atuais. Celso Lafer (1988), num texto em que dialoga com o pensamento de Hannah Arendt, traça um amplo e profundo percurso dos fundamentos jurídicos e filosóficos dos direitos humanos, desde seu nascedouro, até sua reconstrução numa concepção contemporânea. 
Lafer inicia seu percurso - "uma 'arqueologia do saber' jurídico" - peloparadigma do Direito Natural, como fundamento metafísico da função da lei nas sociedades. O primeiro alicerce filosófico em que se assenta o direito é o pressuposto metajurídico da ideia de imutabilidade de certos princípios, que escapam à história, e a universalidade de certos princípios, que escapam à geografia. A tais princípios, "que são dados e não postos por convenção, os homens têm acesso através da razão comum a todos, e são estes princípios que permitem qualificar as condutas humanas como boas ou más" (LAFER, 1988, p. 16).

Ao paradigma do Direito Natural, que resistiu até o século XVIII às tendências de secularização, historicização, positivação, seguese o primado do Direito Positivo, como um novo paradigma que elucida o papel do direito (e dos direitos humanos com sua índole cosmopolita) nas sociedades. O paradigma da Filosofia do Direito, como o designa Lafer - afirma a mutabilidade do direito no tempo e seu particularismo no espaço, uma vez que realça a função do direito como instrumento de gestão e comendo da sociedade, através da técnica das ordens e das proibições, estímulos e desestímulos às condutas humanas. Deixou a ordem jurídica de ser encarada como algo dado pela razão comum e passou a ser vista como algo posto e positivado pelo poder que estabelece, em face de sociedades distintas, o que é lícito ou ilícito.

Lafer faz uma profunda e cuidadosa análise dos vários momentos (gerações) de evolução desse paradigma filosófico, até alcançar um ponto de ruptura. A ruptura, na esteira do pensamento de Arendt, diz respeito ao desconserto epistemológico provocado pela experiência do totalitarismo. Diante de tais absurdos, não tem mais pertinência a lógica do razoável do paradigma da Filosofia do Direito. "O amorfismo jurídico que caracteriza o Estado totalitário torna sem utilidade prática a definição do Direito pela forma" (LAFER, 1988, p. 19).

Após a ruptura, há a emergência da visão contemporânea dos direitos humanos e seu processo de evolução e expansão contínua. Lafer aponta em sua obra, como nesse panorama, marcado pela impossibilidade de um "sistema" para dar sustentáculo a essa ordem de direitos, confronta-se o problema de como julgar um particular, para o qual não existe previamente o dado de um universal. Em face das dificuldades de um juízo absoluto, Arendt explorou o campo dos juízos reflexivos e raciocinantes que entreabrem a faculdade de pensar o particular (retorno a Kant): 
v. 10 (esp) 66-83 ago. 2020
Esta proposta harmoniza-se com a sua visão de raposa perante um mundo percebido centrifugamente, pois a importância dos juízos reflexivos e raciocinantes deriva da relação problemática entre o universal e o particular, que a ruptura tornou evidente. Em síntese: precisamente porque o juízo, no mundo contemporâneo, não pode ser reduzido a uma fórmula inequívoca de subsunção, é que se pode falar no seu peso e na sua responsabilidade (LAFER, 1988, p. 31).

O foco da investigação, neste trabalho, recai sobre dois domínios, duas práticas discursivas particulares que contribuem para a edificação da representação dos direitos humanos nos dias atuais. De um lado, focalizamos os momentos fundamentais dessa construção, dimensão jurídica, mandamental (o sistema jurídico positivo internacional de proteção aos direitos humanos). Recortamos um corpus representativo da rede de práticas discursivas do direito posto e perscrutamos os processos de identificação em curso. De outro lado, precisamos focalizar também as articulações discursivas que são postas em jogo nas formas de identificação que se processam no seio das lutas concretas pela efetivação desses direitos, da prática política e discursiva dos mecanismos institucionais de proteção aos direitos humanos. Tomamos, portanto, neste trabalho, direitos humanos como construto discursivo que emerge e se constitui no seio de práticas sociais diversas, dentre as quais selecionamos duas em particular, a fim de analisar efeitos causais dos elementos textuais sobre a vida social.

Apresentado este breve quadro, passemos ao enquadre metodológico do trabalho.

\section{Delimitação do corpus e percurso metodológico}

Para a ADC, a vida social se organiza em torno de práticas, maneiras habituais pelas quais as pessoas interagem, por meio da aplicação de recursos materiais ou simbólicos. A prática social assim compreendida articula diferentes elementos da vida, ou momentos da prática - ação e interação; relações sociais; pessoas (crenças, valores, atitudes, histórias); mundo material e discurso (FAIRCLOUGH, 2003). Na terminologia de Harvey (1992), vemos cada momento como 'internalizando' os outros sem ser redutível a eles - a relação dialética local correspondente ao relacionamento geral entre os mecanismos discutidos acima.

Para o presente estudo, partimos de um recorte de dois domínios emblemáticos da construção discursiva dos direitos humanos no contemporâneo, duas práticas sociodiscursivas que serão as instâncias de discurso analisadas: 
1. A prática jurídico-normativa internacional de positivação dos direitos humanos: práticas sociais e discursivas de produção, consumo e distribuição da lei, de âmbito internacional, que fixa e regula os direitos humanos;

2. A prática sociodiscursiva de proteção institucional dos direitos humanos: os instrumentos de luta pela efetivação dos direitos humanos; isto é, o contexto da luta, empreendida em contextos institucionais, para que os direitos humanos sejam respeitados.

Como já mencionado, o espaço selecionado para o desenvolvimento da pesquisa foi o contexto de atuação política e social da Comissão de Defesa dos Direitos Humanos da Câmara Municipal de Fortaleza/CE. Dessa forma, segundo o panorama de pesquisa já extensamente abordado aqui, além da investigação dos textos normativos, o trabalho centra-se no estudo dos documentos oriundos da atuação dessa Comissão, em seus empenhos institucionais para tornar efetivos os direitos humanos no seio da sociedade fortalezense e em face de muitas formas de violação.

No domínio das práticas jurídico-normativas, a geração de dados deverá ser feita a partir dos textos normativos mais representativos da ordem jurídica internacional dos direitos humanos. Assim, para a realização deste estudo, analisaremos a Carta Internacional dos Direitos Humanos, composta por três diplomas normativos: a Declaração Universal dos Direitos do Homem, o Pacto Internacional sobre os Direitos Econômicos, Sociais e Culturais e o Pacto Internacional sobre os Direitos Civis e Políticos ${ }^{1}$.

No âmbito das lutas pela efetivação dos direitos humanos, em contextos institucionais, os documentos que servirão ao estudo são relatórios das ações coordenadas empreendidas pela Comissão, pareceres, projetos de lei, entre outros.

Dessa forma, o corpus ampliado da pesquisa engloba a Carta Internacional de Direitos Humanos e todos os documentos que reúnem os resultados dos trabalhos e ações da mencionada Comissão, no biênio 2013-2014.

${ }^{1}$ Ficha informativa sobre direitos humanos, no 2 [ACNUDH]. Disponível em: http://www.gddc. pt/direitos-humanos/Ficha_Informativa_2.pdf. Acesso em: 03 ago. 2016. 
v. 10 (esp) 66-83 ago. 2020

\section{Referencial Teórico: modalidade e identificação}

O significado identificacional diz respeito aos modos de construção de identidades por meio do discurso. Para Fairclough (2003, p. 159), os estilos constituem o aspecto discursivo das identidades, isto é, correspondem aos modos pelos quais o discurso, enquanto linguagem, figura no interior das práticas sociais como modos de ser. Assim, a análise de textos segundo a perspectiva do significado identificacional diz respeito à identificação de atores sociais em textos. Ou, melhor dizendo, diz respeito à consideração das estratégias de linguagem que marcam os gestos de identificação de atores sociais nos textos. Dessa forma, os estilos consistem em formas de texturização de identidades, formas discursivas particulares de ser:

Quem você é em parte uma questão de como você fala, como você escreve, bem como uma questão de encarnação - como você olha, como você mantém a si mesmo, como você se move e assim por diante. Os estilos são ligados à identificação usando a nominalização em vez do substantivo 'identidades' enfatiza-se o processo de identificação, como as pessoas se identificam e são identificadas por outros (FAIRCLOUGH, 2003, p. 159, trad. nossa) $)^{2}$.

A modalidade, categoria analítica proposta por Fairclough (2003) para o significado identificacional, foi tratada por teóricos representantes de estudos com orientações diversas. Ela tem sido uma categoria muito profícua nos estudos da linguagem em uso, por que é muito útil no desvendamento do grau de comprometimento do autor com o seu dizer. A modalidade relaciona-se com a noção de polaridade, com posicionamentos ao longo de uma escala entre "sim" e "não".

Neste trabalho, a modalidade será utilizada nos termos em que Fairclough (2003) a delimitou para operacionalização, fincando as bases de seu raciocínio nos postulados do funcionalismo de Halliday (1994). Vejamos a noção de modalidade para Halliday.

Modalidade significa julgamento do falante das probabilidades, e das obrigações, envolvidas no que ele está dizendo. A proposição pode se tornar discutível por ser apresentada como

\footnotetext{
2 "Who you are is partly a matter of how you speak, how you write, as well as a matter of embodiment - how you look, how you hold yourself, how you move and so forth. Styles are linked to identification - using the nominalization rather than the noun 'identities' emphasizes the process of identifying, how people identify themselves and are identified by others".
} 
provável ou improvável, desejável ou indesejável - em outras palavras, a sua relevância é especificada em termos modais (HALLIDAY, 1994, p. 75, trad. nossa) 3 .

Em sua operacionalização dos postulados da LSF, Fairclough (2003, p. 167) distingue dois tipos de modalidade - epistêmica e deôntica - relacionadas, respectivamente, às trocas de conhecimento e de atividade. Assim, por exemplo, quando estamos diante de afirmações (ou questões), é possível ponderar, em razão das formas linguísticas empregadas, o grau de comprometimento com a verdade de tais afirmações por parte de seu autor. Da mesma forma, quando estamos diante de ofertas (ou demandas), é possível sopesar o grau de comprometimento com a ação da parte daquele que a oferece.

Diante do horizonte teórico proposto, passemos a considerar os dados analisados em meio aos textos produzidos nas práticas discursivas focalizadas.

\section{Análise e discussão dos dados: modalidade e identificação na construção discursiva dos direitos humanos}

Nesta seção do trabalho, serão propostas análises das ocorrências das formas linguísticas de modalidade nos textos oriundos da prática discursiva da lei sobre direitos humanos, assim como da prática discursiva de afirmação desses direitos. Será feito um traçado comparativo das escolhas linguísticas operadas em cada prática, relacionando tais escolhas ao exercício da ideologia e à relação entre discurso e relações de poder.

No que diz respeito à prática sociodiscursiva jurídiconormativa de positivação dos direitos humanos, destacam-se a seguir excertos extraídos dos três diplomas normativos que compõem a Carta Internacional dos Direitos Humanos e que são representativos dos tipos de ocorrência da modalidade mais salientes nessa prática sociodiscursiva. Portanto, as espécies de ocorrência aí exemplificadas se repetem muitas vezes ao longo de todo o texto da Carta, de maneira que constituem estratégias discursivas bem marcantes do modo de construção desse texto. Vejamos as ocorrências destacadas nos excertos abaixo:

\footnotetext{
3 "Modality means the speaker's judgment of the probabilities, or the obligations, involved in what he is saying. A proposition may become arguable by being presented as likely or unlikely, desirable or undesirable - in other words, its relevance specified in modal terms".
} 
v. 10 (esp) 66-83 ago. 2020
Quadro 01 - Excertos da prática jurídico-normativa de positivação dos DH

Artigo $3^{\circ}$ - Toda pessoa tem direito à vida, à liberdade e à segurança pessoal. (DUDH)

Artigo $7^{\circ}$ - Todos são iguais perante a lei e têm direito, sem qualquer distinção a igual proteção da lei. Todos têm direito a igual proteção contra qualquer discriminação que viole a presente Declaração e contra qualquer incitamento a tal discriminação. (DUDH)

Artigo $6^{\circ}$ - O direito à vida é inerente à pessoa humana. Este direito deverá ser protegido pela lei. Ninguém poderá ser arbitrariamente privado de sua vida. (PIDCP) Artigo $5^{\circ}$ - Ninguém será submetido à tortura, nem a tratamento ou castigo cruel, desumano ou degradante. (DUDH)

Artigo $3^{\circ}$ - Os Estados-partes no presente Pacto comprometem-se a assegurar a homens e mulheres igualdade no gozo de todos os direitos civis e políticos enunciados no presente Pacto. (PIDCP)

Artigo $7^{\circ}$ - Os Estados-partes no presente Pacto reconhecem o direito de toda pessoa de gozar de condições de trabalho justas e favoráveis, que assegurem especialmente [...] (PIDESC)

Fonte: Elaborado pela autora.

Tomamos esses casos exemplificativos para comentar, de forma detida, os tipos de modalidade mobilizados nos textos de lei sobre direitos humanos, assim como os efeitos ideológicos dessa mobilização.

Pela análise dos exemplos mencionados acima, podese perceber que, na construção dos textos de lei, são mobilizadas as duas formas de modalidade distinguidas por Fairclough (2003), tanto a epistêmica quanto a deôntica. No que diz respeito à modalidade epistêmica - relativa a trocas de conhecimento - há um enorme predomínio das afirmações, enquanto funções de fala. Fairclough (2003) associa tais escolhas linguísticas ao que ele denomina estilos, isto é, formas de identificação construídas no discurso. Nos exemplos acima, no que toca às formas de identificação, é importante destacar que este predomínio de afirmações se dá na forma de asserções, isto é, afirmações de fatos, o que demonstra um elevado grau de comprometimento com a verdade ${ }^{4}$. Nas afirmações, significativamente numerosas na legislação sobre direitos humanos, há um alto comprometimento com a verdade, de forma que elas não dizem como as coisas "podem ser" ou "seriam", mas sim como as coisas "são". Nos exemplos apontados acima, temos asserções em: "toda pessoa tem direito", "todos são iguais", "todos têm direito", "o direito à vida é inerente" etc.

Esse tipo de uso, que denota máximo comprometimento do autor com seu dizer, é o preponderante na texturização da Carta, notadamente no texto da Declaração Universal dos Direitos do Homem. Isso é muito significativo do direcionamento desse texto quanto à 
construção de seus sentidos, já que se trata da positivação de um regime de verdade. Como se trata de uma "troca de conhecimento", o que está em jogo nas afirmações são informações, saberes sobre o mundo. Nesse caso, a afirmação peremptória, de máximo comprometimento, denota que a lei "reflete" as realidades sobre as quais fala, e não as representa ou refrata. Sabemos que, na prática, os homens não "são" sempre tratados igualmente, a vida não "é" pleno direito humano. Muitas das realidades, tais como a fome e a miséria, contradizem diretamente essa asserção peremptória, daí a ideia de comprometimento. Afirmar esses sentidos como verdades, representa um compromisso com essa verdade, com impactos sobre a sociedade. A forma linguística, embora revestida de uma afirmação, apresenta valor modal epistêmico menor que o valor deôntico. Existe um valor deôntico implícito. Este fenômeno é típico do discurso jurídico que se volta não para dizer o "ser", mas o "dever ser".

No que diz respeito à modalidade deôntica, encontramos nos excertos dois tipos de ocorrência, ambas envolvendo ofertas: comprometimento e proibição. Aqui estão envolvidas trocas de atividade, isto é, há "ações" em jogo nas trocas verbais; demanda-se algo, oferece-se algo. Os bens jurídicos assegurados na ordem de direito em estudo apresentam-se, de forma geral, com usos que representam o compromisso do autor com uma ação, a promessa de uma ação, ou a sua negativa.

Observemos, por exemplo, os seguintes usos: "este direito deverá ser protegido", os Estados-partes "comprometem-se", "reconhecem". Nesses casos, estamos diante de formas de cometimento, compromissos do autor em proceder de uma certa maneira. Quando esse compromisso não se manifesta afirmativamente, como nos exemplos anteriores, ele se apresenta de forma negativa, resultando em proibições, recusas a realizar algum tipo de ação: "ninguém poderá ser", "ninguém será". Essas escolhas linguísticas, da mesma forma que as percebidas nas ocorrências da modalidade epistêmica, são muito típicas dos textos legislativos, uma vez que esses textos têm o condão de fixar uma ordem de condutas (ações) a serem realizadas, sob pena das cominações legais.

Resta demonstrado que o quadro dos casos de modalidade mais significativos na composição dos textos da prática jurídico-normativa sobre direitos humanos possui a seguinte configuração: 
v. 10 (esp) 66-83 ago. 2020

Quadro 02 - Tipos de modalidade (prática jurídico-normativa)

\begin{tabular}{|l|l|l|}
\hline & Forma da ocorrência & Exemplos \\
\hline $\begin{array}{l}\text { Modalidade Epistêmica } \\
\text { (compromisso com a } \\
\text { verdade) }\end{array}$ & Asserção peremptória & $\begin{array}{l}\text { "toda pessoa tem direito", } \\
\text { "todos são iguais", "todos } \\
\text { têm direito", "o direito à } \\
\text { vida é inerente" etc. }\end{array}$ \\
\hline $\begin{array}{l}\text { Modalidade Deôntica } \\
\text { (compromisso com uma } \\
\text { ação) }\end{array}$ & $\begin{array}{l}\text { Cometimento / } \\
\text { Comprometimento }\end{array}$ & $\begin{array}{l}\text { "este direito deverá ser } \\
\text { protegido", os Estados- } \\
\text { partes "comprometem-se", }\end{array}$ \\
\cline { 2 - 3 } & "reconhecem" etc. \\
\cline { 2 - 3 } & Proibição / Recusa & "ninguém poderá ser", \\
& "ninguém será" etc. \\
\hline
\end{tabular}

Fonte: Elaborado pela autora.

Como foi possível perceber pelos dados, as formas de modalidade empregadas nos textos normativos em estudo referem-se a compromissos assumidos por parte do sujeito, como indício linguístico de seu processo de identificação. O sujeito compromete-se com a "verdade" do que diz ou com a obrigatoriedade / necessidade daquilo que se diz. Como se trata de um discurso jurídico prescritivo, vemos um processo de apagamento, esvaziamento da figura do sujeito. As afirmações peremptórias, as vedações e cometimentos condizem com a construção de um regime de verdade, isto é, uma ordem mandamental cuja legitimidade última radica-se em uma verdade absoluta, uma ontologia. O efeito ideológico mais significativo dessas escolhas é a naturalização dos discursos em que estão inculcadas as identidades assim construídas. Um efeito de objetividade (no sentido de não-sujeito), de transparência, de representatividade máxima (tradução especular dos anseios máximos da natureza humana).

O discurso da lei não pode se assumir como discurso político, embora, como vimos por exemplo quando analisamos os modos de agir e representar, haja forças políticas em confronto, haja uma história na base de cada posicionamento, haja investimentos ideológicos dos sentidos. Enquanto produtos de linguagem, as normas, os textos normativos refletem e refratam aspectos micro e macroestruturais da sociedade que constitui seu nascedouro e enredam-se, por esse motivo, na mesma trama dos conflitos hegemônicos e disputas por poder que estão na base das relações sociais humanas. A própria negação do caráter sensivelmente político e ideológico das identidades sociais dos sujeitos envolvidos na produção, distribuição e consumo dos textos jurídicos normativos constitui uma tomada de posição no campo do saber que merece atenção crítica. 
A construção de identidades sociais na prática jurídiconormativa investigada não se desenvolve de maneira neutra ou isenta de escolhas de ordem política e ideológica. Na verdade, considerando essa prática sociodiscursiva, a emergência de novos sentidos para os direitos humanos no mundo contemporâneo se dá pela mobilização de muitas expressões modalizadas, principalmente as formas categóricas, assim como por usos linguísticos que denotam avaliação, apreciação, e que apontam, portanto, para processos de identificação dos sujeitos que os afirmam e defendem. Sujeitos com valores, crenças, história.

Passemos agora a investigar, no que diz respeito à identificação, a rede de práticas sociais e discursivas que caracteriza a atuação concreta de órgãos institucionais de proteção aos direitos humanos, representados neste estudo pela Comissão de Direitos Humanos da Câmara Municipal de Fortaleza. Consideramos o contexto de atuação desse órgão emblemático da luta em prol da afirmação dos direitos humanos enquanto ordem de direitos, conjunto de institutos (instituições) jurídico-políticas protetivas e garantidoras da higidez do princípio da dignidade humana, quando em face de situações reais de violação. A dimensão da luta será, portanto, tomada, neste estudo, como parte fundamental da construção contemporânea dessa representação tão problemática, que vem sendo objeto de intenso debate, de profundas e contínuas reformulações. No interior dessas práticas, o aspecto normativo, (as dimensões institucional e jurisdicional) está presente nas ações (intervenções) de edificação do terreno social no que diz respeito à representação de direitos humanos.

Depois que foi empreendido esse estudo das formas linguísticas de identificação do domínio das práticas normativas de fixação dos direitos humanos, passemos à consideração das ocorrências que caracterizam a prática de luta institucional por direitos. No que toca às escolhas linguísticas manifestas nos documentos produzidos nas ações da Comissão, a mobilização de formas modalizadas é significativamente mais variada. Observemos os seguintes excertos: 
v. 10 (esp) $66-83$ ago. 2020
Quadro 03 - Excertos prática de proteção institucional aos DH

(1) Este documento constitui-se em um demonstrativo dos esforços da Comissão (p.1 $\mathrm{RCDH})$

(2) Por fim, é importante destacar que os trabalhos desenvolvidos (p.1, RCDH)

(3) Em comum, acredito, podem ser práticas coordenadas que se inserem em uma onda de violência em que grupos de extermínio ou milícias, alguns até com ramificação em instituições policiais, agem deliberadamente. Aqui, neste relato, destaco três casos emblemáticos, os quais foram nos trazido via as entidades acima citadas (p. 1, RIEJ)

(4) Também gostaria de ressaltar que esta realidade descrita está baseada apenas nos dois meses de 2014 e se refere a crimes envolvendo jovens focados na cidade de Fortaleza e Região Metropolitana. (p. 3, RIEJ)

(5) Assim, sugiro que essa Comissão de Direitos Humanos da Câmara Federal possa aprovar e realizar diligência a nossa cidade no intuito de fortalecer a incidência política e institucional que cobra processos de investigação céleres (p. 4, RIEJ)

(6) Convidamos todos e todas a conhecerem um pouco melhor as atividades dos últimos dois anos. Boa leitura! (p. 1, RCDH)

(7) Além disso, sinto-me preocupado com a crescente violência que envolve a juventude, principalmente quanto à letalidade juvenil na Grande Fortaleza. (p.3, RIEJ) Fonte: Elaborado pela autora.

Inicialmente, é importante pontuar que, como se trata de uma rede de práticas discursivas institucionais, ainda persiste uma intenção de objetividade como pano de fundo para a construção desses discursos. Na análise do corpus ampliado dos documentos da comissão, os textos predominantemente mobilizam o gênero técnico formal relatório administrativo. Dessa forma, há um número significativo de usos de linguagem que se classificam como "afirmações", enquadrando-se, portanto, na modalidade epistêmica, como expressão de uma forma categórica de modalidade. Esse tipo de escolha linguística tem a forma de uma afirmação categórica, que, como vimos, também é extremamente comum nos textos normativos. Dentre os excertos apontados acima, os exemplos (1) e (2) ilustram esse tipo de modalidade.

Contudo, nós já dissemos que os documentos produzidos pela Comissão, como resultado de suas ações concretas, são muito permeáveis à influência dos outros discursos que compõem a ampla cadeia de práticas sociais de luta por direitos. Nesse sentido, esses documentos são bem mais emblemáticos do pluralismo, da profusão de demandas particulares. A análise das formas de modalidade ilustra bem isso. Em termos da modalidade epistêmica, por exemplo, além das afirmações de fato mencionadas, que denotam alto compromisso com a verdade, há usos modalizados, intermediários. Os excertos (3) e (4) ilustram o emprego de afirmações sutilmente diferentes em termos do uso da modalidade epistêmica. Nesses casos, não se afirma como as coisas são, mas sim 
como podem ser, há uma relativização acerca da verdade daquilo que se afirma. No caso da ocorrência (3), estamos diante de uma afirmação modalizada, em um grau médio de comprometimento com a verdade, sinalizada pela presença de uma locução verbal modal "podem ser" e pelo emprego de um verbo indicativo de fenômeno mental "acredito". No caso do excerto (4), percebe-se o emprego de um verbo indicativo de fenômeno mental "gostaria", como recurso de polidez. É importante mencionar que, explicitamente, se trata de modalidade epistêmica, mas, implicitamente, o sentido em questão é de ação (portanto, modalidade deôntica), de compromisso médio com uma ação de troca de informação. Trata-se de uma forma de polidez também, e uma maneira de suavizar o discurso - com natureza claramente política.

Em termos de modalidade deôntica, nos exemplos (5) e (6) estamos em face de demandas modalizadas. Em ambas, o autor não se compromete completamente com a obrigatoriedade de uma ação por parte do leitor, mas a incentiva. As expressões "convidamos" e "sugiro" indicam isso com clareza. É interessante observar quanto a esses usos que, além de constituírem formas de suavizar o discurso, não impondo, mas sugerindo, também representam uma mescla entre discurso formal e informal, uma abertura do discurso do relatório para uma dimensão de ação, com marca de subjetividade. Isso é muito bem ilustrado no exemplo (6) cuja linguagem se "desvia" da forma do relatório, e muda o tom do discurso para uma espontaneidade, que pode ser reforçada pela presença da exclamação "Boa leitura!".

Essas observações nos levam a pontuar mais uma espécie de ocorrência importante na redação dos relatórios: a presença da subjetividade. Percebemos, entre os exemplos apontados, muitos vestígios de subjetividade, tais como o emprego de verbos em primeira pessoa (inclusive nos exemplos já comentados). Quanto à modalidade subjetiva, o exemplo (7) é especialmente ilustrativo, por que traz muitos elementos linguísticos que denotam subjetividade: verbo indicativo de processo mental afetivo, o chamado adjetivo verbal (particípio de valor adjetivo), além do advérbio intensificador.

O quadro dos tipos de modalidade presentes nos textos das práticas de proteção institucional dos direitos humanos é o seguinte: 
v. 10 (esp) 66-83 ago. 2020

Quadro 04 - Tipos de modalidade (prática institucional de proteção)

\begin{tabular}{|l|l|l|}
\hline & Forma da ocorrência & Exemplos \\
\hline $\begin{array}{l}\text { Modalidade Epistêmica } \\
\text { (compromisso com a } \\
\text { verdade) }\end{array}$ & $\begin{array}{l}\text { Asserção peremptória } \\
\text { (compromisso alto) }\end{array}$ & $\begin{array}{l}\text { "constitui-se", "é } \\
\text { importante" }\end{array}$ \\
\cline { 2 - 3 } $\begin{array}{l}\text { Afirmação modalizada } \\
\text { (compromisso médio) }\end{array}$ & $\begin{array}{l}\text { "acredito, podem ser", } \\
\text { "gostaria de ressaltar" }\end{array}$ \\
\hline $\begin{array}{l}\text { Modalidade Deôntica } \\
\text { (compromisso com uma } \\
\text { ação) }\end{array}$ & $\begin{array}{l}\text { Demanda modalizada } \\
\text { (compromisso médio com a a } \\
\text { necessidade da ação) }\end{array}$ & "sugiro", "convidamos" \\
\hline Modalidade Subjetiva & $\begin{array}{l}\text { "sinto-me preocupado", } \\
\text { "principalmente", "Boa } \\
\text { leitura!" etc. }\end{array}$ \\
\hline
\end{tabular}

Fonte: Elaborado pela autora.

Todos os vestígios comentados apontam para a consideração de que os textos construídos no seio das lutas institucionais pela efetivação dos direitos humanos são mais assumidamente políticos. Eles exibem de forma mais clara os posicionamentos ideológicos, as responsabilidades sociais, os agentes históricos envolvidos no processo de construção dos sentidos (THOMPSON, 2009).

Assim, é importante, para a compreensão do discurso jurídico e para a construção discursiva dos direitos humanos na lei e na luta, compreender identidades e diferenças como construtos culturais, produções simbólicas; e, portanto, instáveis, sujeitas a relações de poder e a lutas por sua (re)definição. A afirmação da identidade e da diferença no discurso materializa lutas hegemônicas, conflitos de poder entre grupos assimetricamente situados (THOMPSON, 2009).

Já foi dito neste trabalho que existe uma relação dialética de interdependência entre os três tipos de significado. De fato, a noção de "tipos de significado" diz respeito a uma compreensão do discurso em sua relação indissociável com as práticas sociais nas quais se insere (CHOULIARAKI; FAIRCLOUGH, [1999] 2007). Nas práticas, o discurso se materializa em maneiras de significar como modos de agir, de representar e de ser. Fairclough (2003) é preciso na formulação da relação dialética do significado identificacional com os demais:

Como alguém representa o mundo, com o que alguém se compromete, por exemplo, o grau de compromisso de alguém com a verdade, é uma parte de como se identifica a si mesmo, necessariamente, em relação aos outros com quem está interagindo. Colocando de forma diferente, as identidades são 
relacionais: o que alguém é é uma questão de como se relaciona com o mundo e com outras pessoas (FAIRCLOUGH, 2003, p. 166, trad. nossa) 5 .

Dessa forma, no âmbito do significado identificacional, o estudo da modalidade é importante indício dos modos de construção de identidades nos discursos. A reflexão a partir de expressões modais permite desenvolver um estudo aprofundado dos modos de identificação no discurso jurídico da lei e da luta por direitos humanos. Essas análises podem conduzir ao questionamento de estratégias hegemônicas empregadas nesse discurso, assim como à problematização da política de representação nele inserida, legitimando esquemas classificatórios e exclusões.

\section{Considerações finais}

Como pudemos perceber neste trabalho, os direitos humanos vêm sendo concebidos contemporaneamente como plataforma emancipatória de direitos voltados para a preservação da higidez da dignidade humana. Gestados no seio do discurso do direito tendo como fundamento uma representação universal em termos clássicos, isto é, uma visão essencialista do humano, sua construção contemporânea traz impressa a marca da particularização, da singularidade que atravessam os contextos de violação (exclusão). Como vimos, isso instaura a problemática do que é o universal em sua relação mutuamente constitutiva com o particular na construção desse objeto de direito.

Esta problemática, simultaneamente linguística, jurídica e sociológica, foi abordada tendo como referencial teórico fundamental a Análise de Discurso Crítica, de Norman Fairclough ([1992] 2001, 2003), com sua visão crítica e emancipatória do discurso em relação indissociável com o mundo social. É notadamente no caráter emancipatório da abordagem faircloughiana que se acentua sua orientação crítica. Segundo esse viés, a linguagem nos convida continuamente a intervir sobre ela, com o fim de desvelar posicionamentos ideológicos, relações de dominação e esquiva, disputas por poder, que são travadas em seu interior.

\footnotetext{
5 "How one represent the world, to what one commits oneself, e.g. one's degree of commitment to truth, is a part of how one identifies oneself, necessarily in relation to others with whom one is interacting. Putting it differently, identities are relational: who one is is a matter of how one relates to the world and to other people".
} 
v. 10 (esp) 66-83 ago. 2020

O foco desenvolvido no presente estudo sobre a construção desses direitos enquanto construto discursivo, cuja formação assenta-se em articulações discursivas marcadas por uma relação complexa entre o universal e o particular, revela um ponto de vista consequente acerca de alguns aspectos da configuração do mundo social contemporâneo, seus conflitos e suas tensões.

Pudemos perceber como as estratégias articulatórias mobilizadas para construir sentidos para a representação de direitos humanos se diferenciam de uma prática discursiva para a outra. No âmbito da justiça internacional humanitária, o universal - visão essencialista do homem - é tomado como o fundamento, como aquilo que torna possível a representação universalizante de direitos humanos. No contexto institucional de proteção, o processo é contrário: o fundamento advertido para a luta política é a singularidade, a experiência/vivência cotidiana, as particularidades comunitárias que são revestidas de um discurso universalizante para auferir mais força.

Tomando como pontos de partida fundamentais as práticas discursivas focalizadas e a articulação teórica proposta, procuramos refletir sobre as articulações discursivas operadas na construção de sentidos para esse rol de direitos nos domínios particulares observados, procurando observar os gestos de linguagem empreendidos para significar esses direitos. Um dos desdobramentos fundamentais desses propósitos analíticos diz respeito à ponderação de como essas articulações discursivas, marcadas pela contingência e pela precariedade, contribuem para entender a relação entre discurso e poder, notadamente o discurso jurídico. Nesse particular, é pertinente a reflexão de Santos (2003) acerca da possibilidade de um direito emancipatório.

Reinventar, neste caso, revela-se tarefa especialmente complexa, porquanto, se a revolução parece uma possibilidade definitivamente descartada, já o direito se acha mais difuso do que nunca, preenchendo mesmo os espaços sociais e políticos abertos pelo colapso da revolução. Para os conservadores, não há aqui nada a reinventar, exceptuando talvez modos cada vez mais subtis (e não tão subtis quanto isso) de desmantelar os mecanismos através dos quais liberais e demo-socialistas transformaram o direito em instrumento da mudança social. A tarefa científica e política que se nos coloca pela frente pode ser formulada da seguinte maneira: como reinventar o direito para lá do modelo liberal e demo-socialista e sem cair na agenda conservadora - e, mais ainda, como fazê-lo de modo a combater esta última de modo mais eficaz (SANTOS, 2003, p. 8). 
É disso que se trata tomar um corpus jurídico e empreender uma análise de discurso, inculcada em práticas sociais: reinventar o direito, com fins emancipatórios. Os dados analisados até aqui sinalizam que o horizonte contextual de construção da representação de direitos humanos será sempre distinto quando no âmbito normativo (nos textos de lei exprimem essa ordem, exemplificados aqui na Carta Internacional dos Direitos Humanos), no domínio jurídico-processual (nas ações instauradas como forma de reivindicar a tutela e higidez de tais direitos nos espaços institucionais, pela mobilização de poderes jurisdicionais, seja no âmbito interno, seja no internacional), no seio das práticas de militância (nas formas de ação e reivindicação por justiça quando mobilizados como principal bandeira de luta frente a situações reais de violação em espaços de exclusão), entre outros contextos.

\section{Referências bibliográficas}

CHOULIARAKI, Lilie; FAIRCLOUGH, Norman. Discourse in late modernity: rethinking critical discourse analysis. Edinburg: Edinburg University Press: [1999] 2007.

EGGINS, Suzanne. An introduction to systemic functional linguistics. London, New York: Pinter Publishers, 1994.

FAIRCLOUGH, Norman. Discurso e mudança social. Brasília: Editora Universidade de Brasília, [1992] 2001.

FAIRCLOUGH, Norman. Analysing discourse: textual analysis for social research. London: Routledge, 2003.

HALLIDAY, Michael Alexander Kirkwood. An introduction to functional grammar. 2. ed. London: Edward Arnold, 1994.

HARVEY, David. A condição pós-moderna. 17. ed. São Paulo: Loyola, 1992.

HUMAN RIGHTS WATCH. Human Rights Watch World Report 1994: Events of 1993. New York: Human Rights Watch, 1994. p. Xx.

LAFER, Celso. A reconstrução dos direitos humanos: um diálogo com o pensamento de Hannah Arendt. São Paulo: Companhia das Letras, 1988.

PIOVESAN, F. Direitos humanos e justiça internacional. 2. ed. São Paulo: Saraiva, 2011.

SANTOS, Boaventura de Sousa. "Poderá o direito ser emancipatório?" Revista crítica de ciências sociais, n. 65, p. 7-76, maio, 2003.

THOMPSON, John Brookshire. Ideologia e cultura moderna: teoria social crítica na era dos meios de comunicação de massa. Petrópolis: Vozes, 2009. 